INTERNATIONAL RESEARCH JOURNAL OF PHARMACY

www.irjponline.com

ISSN $2230-8407$

Research Article

Research Article

\title{
CHARACTERIZATION OF PAPAYA FRUIT MEDIATED SILVER NANOPARTICLES AND EVALUATION OF ITS ANTIMICROBIAL AND WOUND HEALING ACTIVITY
}

EnamalaNarmadha, Hemashenpagam N*, SathiyaVimal. S, VasanthaRaj S

PG and Research Department of Microbiology, Hindusthan College of Arts and Science, Coimbatore-28, India

*Corresponding Author Email: drhemashenpagam@gmail.com

Article Received on: 10/05/13 Revised on: 01/06/13 Approved for publication: 11/07/13

DOI: $10.7897 / 2230-8407.04737$

IRJP is an official publication of Moksha Publishing House. Website: www.mokshaph.com

(C) All rights reserved.

\section{ABSTRACT}

The field of Nanotechnology is the most active area of research in modern material science. Though there are many chemical as well as physical methods, green synthesis of nanomaterial is the most emerging method of synthesis. We report the synthesis of antibacterial silver nanoparticles using Papaya. The synthesized AgNPs have been characterized by UV-Vis spectroscopy and SEM microscopy. The silver nanoparticles stabilized by Papaya fruit extract were found to have enhanced antimicrobial activity against well-known pathogenic strains Klebsiella pneumonia, Pseudomonas aeruginosa, Staphylococcus aureus, Proteus vulgaris and E. coli.

Keywords: Papaya extract, Soxhlet, Silver nanoparticles, SEM, Antimicrobial activity.

\section{INTRODUCTION}

The field of nanotechnology is one of the most active research areas in modern materials science. Nanoparticles exhibit new or improved properties based on specific characteristics such as size, distribution and morphology ${ }^{1}$. There have been impressive developments in the field of nanotechnology in the recent years, with numerous methodologies developed to synthesize nanoparticles of particular shape and size depending on specific requirements. New applications of nanoparticles are increasing rapidly ${ }^{2}$. Nanotechnology is also being utilized in medicine for diagnosis, therapeutic drug delivery and the development of treatments for many diseases and disorders. Nanotechnology is an enormously powerful technology, which holds a huge promise for the design and development of many types of novel products with its potential medical applications on early disease detection, treatment and prevention ${ }^{3}$. Nanoparticles, generally considered as particles with a size up to $100 \mathrm{~nm}$, exhibit completely new or improved properties as compared to the larger particles of the bulk material that they are composed based on specific characteristics such as size, distribution and morphology ${ }^{4}$. Nanoparticles of noble metals, such as gold, silver and platinum are widely applied in products that directly come in contact with the human body such as shampoos, soaps, detergent, shoes, cosmetic products and toothpaste, besides medical and pharmaceutical applications. Therefore, there is a growing need to develop environmentally friendly processes for nanoparticle synthesis without using toxic chemicals ${ }^{5}$. Nanotechnology is emerging as a rapidly growing field with its application in science and technology for the purpose of manufacturing new materials at the nanoscale level. In the present scenario, nanoscale materials have emerged up as novel antimicrobial agents owing to their high surface area to volume ratio and the unique chemical and physical properties ${ }^{6,7}$. Nanotechnology is now creating a growing sense of excitement in the life sciences especially biomedical devices and Biotechnology ${ }^{8}$. It is confirmed that silver nanoparticles are capable of rendering high antifungal efficacy and hence has a great potential in the preparation of drugs used against fungal diseases. ${ }^{9}$

\section{MATERIALS AND METHODS}

\section{Collection of fruit Materials}

Mature fruit of Papaya were collected from Coimbatore, Tamil Nadu, India. The leaves of Papaya were washed thoroughly three times with water and once with distilled water. The plant materials were air dried and powdered. The powdered samples were hermetically sealed in separate polythene bags until the time of extraction.

\section{Preparation of fruit Extract}

$10 \mathrm{~g}$ of fruit was extracted successively with $100 \mathrm{ml}$ of methanol at $40-50^{\circ} \mathrm{C}$ in Soxhlet extractor until the extract was clear. The extracts were evaporated to dryness and the resulting pasty form extracts were stored in a refrigerator at $4^{\circ} \mathrm{C}$ for future use ${ }^{10,11}$.

\section{UV-Vis spectral analysis}

After incubation, the colour change in fruit extract was compared with control and sample. Synthesized silver nanoparticles was confirmed by sampling the aqueous component and the absorption maximum was scanned by UV Vis spectrometer at the wavelength $400-450 \mathrm{~nm}$ on PerkinElmer Lambda 25 spectrophotometer. Based on the absorbance value and peak it shows that which plant extract has the highest ability to synthesize nanoparticles.

\section{Test Microorganisms}

The pathogenic bacteria, viz., Staphylococcus aureus, Escherichia coli, Klebsiella pneumonia, Proteus vulgaris and Pseudomonas aeruginosa species of bacteria were used during the present study and were obtained from PSG Hospital, Coimbatore, India. The cultures were sub-cultured and maintained on Nutrient agar slants and stored at $4{ }^{\circ} \mathrm{C}$.

\section{Antibacterial Activity}

Muller Hinton Agar plates were prepared, sterilized and solidified. After solidification, the bacterial cultures were swabbed on these plates. Then the well of the suitable size (6 $\mathrm{mm}$ in diameter) was cut in each plate. The synthesized nanoparticles were concentrated by centrifugation and the pellets were added an each well. It was then incubated at 
$37^{\circ} \mathrm{C}$ for $24 \mathrm{~h}$. The plates were examined for inhibitory zones $^{12}$.

\section{Particle size analysis}

It was performed at Karunya University, Coimbatore, India. The particle size distribution of silver nanoparticles was evaluated using dynamic light scattering (DLS) measurements conducted with a Malvern zetasizer Nano series compact scattering spectrometer. Data obtained were analyzed using zetasizer software.

\section{Lyophilization}

$3 \mathrm{ml}$ of sample (plant extract and silver nitrate) was placed in a round bottom flask which was placed in a pre- freezing bath for about $2 \mathrm{~h}$. After that this was placed in a lyophilizer and proper vacuum was maintained at this stage the temperature was set to $47^{\circ} \mathrm{c}$. All the screws were tightened to which the flask was attached and the crystallization process started and the excess water was removed. The lyophilized sample was obtained in the powdered form and this was stored later.

\section{SEM analysis}

The structural characters of nanoparticles were detected by SEM analysis. It was performed at Karunya University, Coimbatore, India.

\section{Microorganisms for wound healing activity}

Wound healing activity was carried out using band aid. The Johnson and Johnson band aid was purchased.

Table 1: Antibacterial Activity of Papaya Sample against Bacterial Pathogens

\begin{tabular}{|c|c|c|c|}
\hline Organism & Plant Extract (mm) & Silver Nitrate (mm) & Sample (mm) \\
\hline Pseudomonas aeruginosa & - & $9 \mathrm{~mm}$ & $18 \mathrm{~mm}$ \\
\hline Klebsiella pneumoniae & - & - & $15 \mathrm{~mm}$ \\
\hline Staphylococci aureus & - & - & $23 \mathrm{~mm}$ \\
\hline Proteus vulgaris & - & $10 \mathrm{~mm}$ & $14 \mathrm{~mm}$ \\
\hline E. coli & $11 \mathrm{~mm}$ & $12 \mathrm{~mm}$ & $17 \mathrm{~mm}$ \\
\hline
\end{tabular}

UV-Vis Absorption Spectroscopy Analysis of Silver Nanoparticles Synthesized from Papaya

SYSTRONICS

DOUBLE BEAM UV-VIS Spectrophotometer: 2201
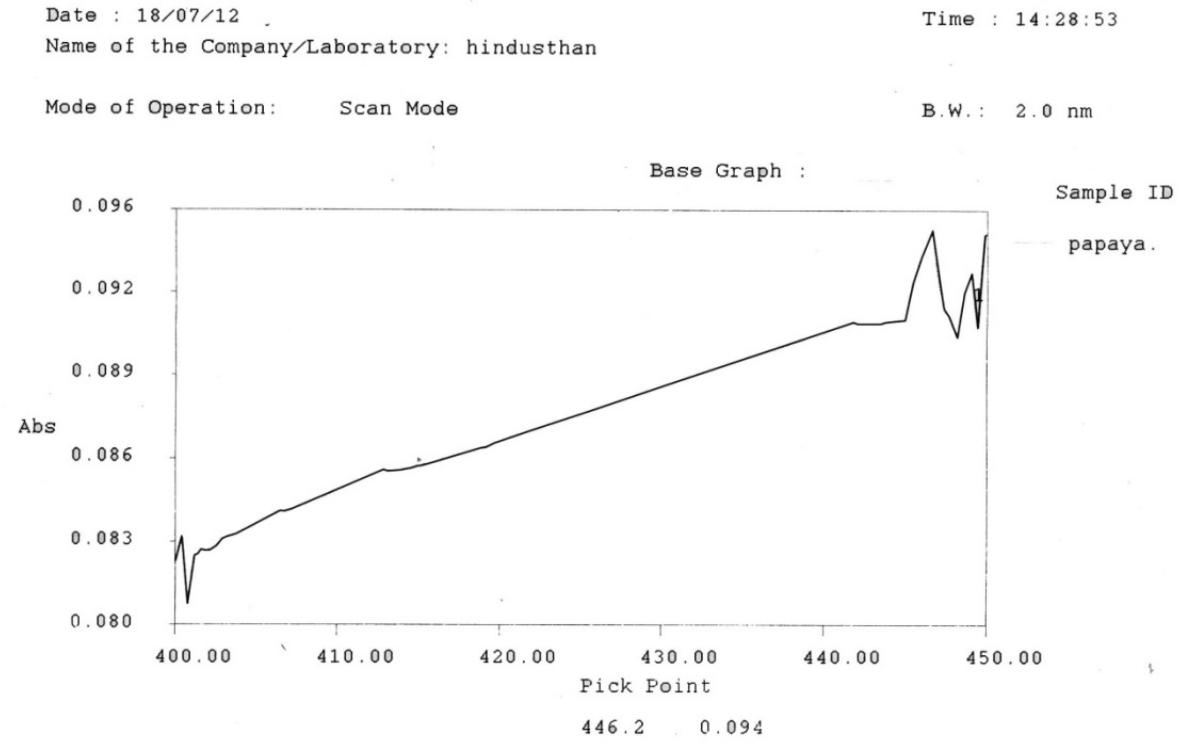

Figure 1: Papaya Sample 


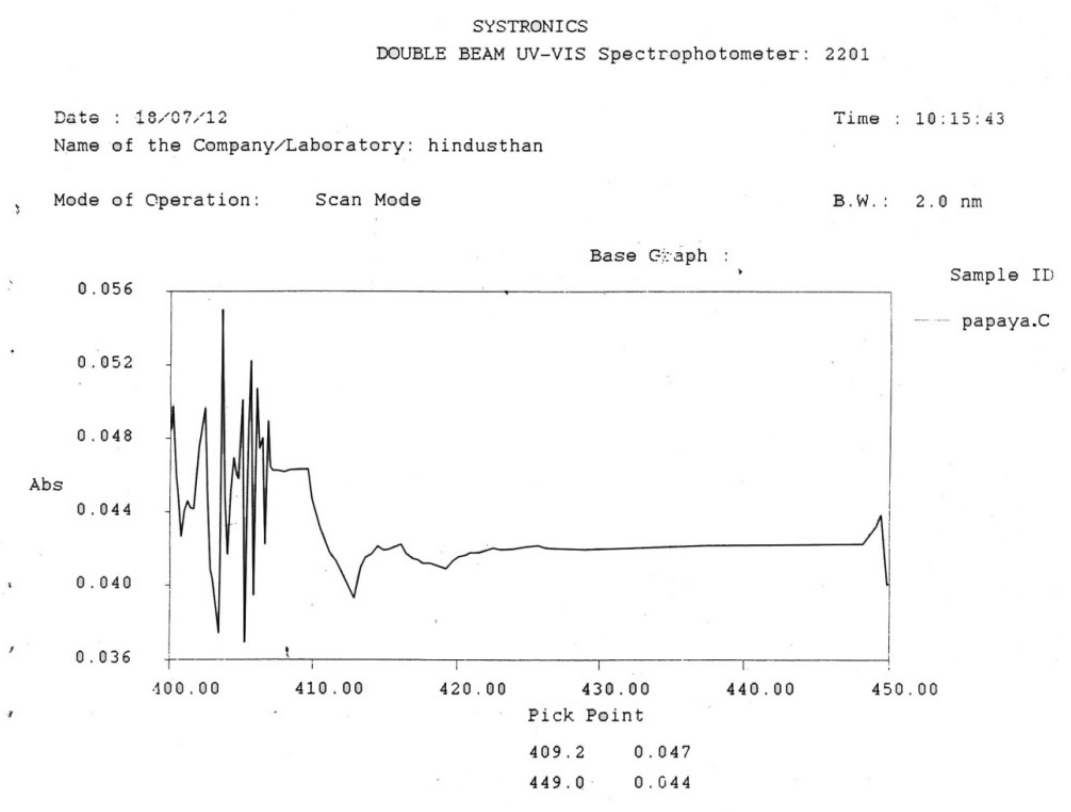

Figure 2: Papaya Control
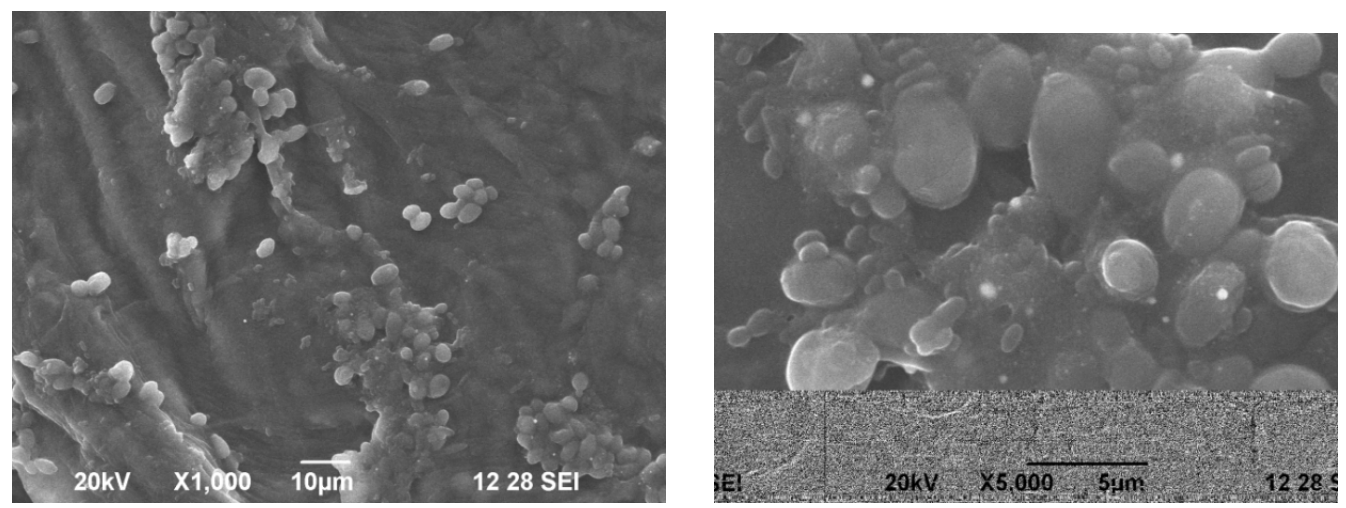

Figure 3: Scanning Electron Microscopy (SEM)

\section{RESULTS AND DISCUSSION}

The green synthesis of silver nanoparticles through fruit extracts were carried out. It is well known that silver nanoparticles exhibit yellowish-brown colour in aqueous solution due to excitation of surface Plasmon vibrations in silver nanoparticles ${ }^{13}$. The appearances of yellowish-brown colour in the reaction vessels suggest the formation of silver nanoparticles $(\mathrm{SNPs})^{14}$. Silver nitrate is used as reducing agent as silver has distinctive properties such as good conductivity, catalytic and chemical stability. The time duration of change in colour varies from plant to plant. The synthesis of SNPs had been confirmed by measuring the UVVis spectrum of the reaction media. The UV-Vis spectrum of colloidal solutions of SNPs synthesized from, Papaya has absorbance peaks at 400 to $450 \mathrm{~nm}$ at $24 \mathrm{~h}$ and $48 \mathrm{~h}$ (Figure 1 and 2). Toxicity studies on pathogen opens a door for nanotechnology applications in medicine. Papaya extract produce the maximum zone of inhibition in Staphylococcus aureus $(23 \mathrm{~mm})$ and the minimum zone of inhibition was produced by Proteus vulgaris $(14 \mathrm{~mm})$ (Table 1). The fruit sample was freeze dried, sonicated with distilled water, small drop of this sample was placed on glass slide allowed to dry ${ }^{15}$ revealed that there were two peaks in the beginning and they continue to exist even up to $24 \mathrm{~h}$ with slight increase in intensity. This indicates non-uniform distribution of size in the beginning of the reaction. A thin layer of platinum was coated to make the samples conductive Jeol JSM-6840 LV SEM machine was operated at a vacuum of the order of 10-5 torr. The accelerating voltage of the microscope was kept in the range 10-20 kv. Compositional analysis carried on the sample. The sample was sent Tokarunya University, Coimbatore, India (Figure 3).

\section{CONCLUSION}

The present study included the bio-reduction of silver ions through medicinal plants extracts and testing for their antimicrobial activity. The aqueous silver ions exposed to the extracts, the synthesis of silver nanoparticles were confirmed by the change of colour of plant extracts. These environmentally benign silver nanoparticles were further confirmed by using UV-Vis spectroscopy and SEM analysis. It is confirmed that silver nanoparticles are capable of rendering high antibacterial efficacy and hence has a great potential in the preparation of drugs used against bacterial diseases. 


\section{REFERENCES}

1. Bhainsa KC and Souza SF. Extracellular biosynthesis of silver nanoparticles. Colloids and surfaces B: Biointerfaces 2006; 47: 160-164. http://dx.doi.org/10.1016/j.colsurfb.2005.11.026 PMid:16420977

2. Ankanna S, Prasad TNVK, Elumalai EK, Savithramma N. Production of biogenic silver nanoparticle using Boswellia ovalifoliolata stem bark. Digest journal of nanomaterial and biostructures 2010; 5(2): 369-372.

3. Bar H, Bhui DK, Sahoo GP, Sarkar P and Misra A. Green Synthesis of silver nanoparticles using latex of Jatraphacurcas. Collids and surfaces A: Physicochemical and engineering aspects 2009; 339:134-139.

4. Joerger R, Klaus $\mathrm{T}$ and Granquist CG. Biologically produced silvercarbon composite materials for optically thin film coatings. Advances materials 2000; 12: 407-409. http://dx.doi.org/10.1002/(SICI)15214095(200003)12:6<407::AID-ADMA407>3.0.CO;2-O

5. Ahmad A, Senapati S, Khan MI, Kumar R, Srinivas V and Saster M. Intracellular synthesis of gold ananoparticles by a novel alkalotolerantspecies. Nanotechnology 2003; 14: 824-828. http://dx. doi.org/10.1088/0957-4484/14/7/323

6. Morones JR and Elechiguerra JL. Alejandra Camacho, Katherine Holt, Juan B Kouri, Jose Tapia Ramírez and Miguel Jose. Yacaman Nanotechnology 2005; 23-46.

7. Kim JS, Kuk E, Yu KN, Kim JH, Park SJ, Lee HJ, Kim SH and Park YK. Nanomed Nanotechnol Biol Med 2007; 3(1): 95-101.

8. Prabhu N, Divya TR, Yamuna G. Digest J Nanomater Biostruct 2010; 5: 185-189.
9. Vasantharaj S, Sathiyavimal S and Hemashenpagam N. Antimicrobial Activity of Silver Nanoparticle Synthesized by Using Costusigneus. Res. J. Pharm. Bio and Che. Sci 2013; 733-738.

10. Anjaiah A, Harogopal V, Ragavander KBP and Chandrasekhar EL. Effect of full thickness skin grafts and mesh skin grafts on granulating wounds in dogs, Experimental study 2001; 92-94.

11. Chessbrough M. Medical laboratory manual for Tropical countries, Linacre House, Jordan Hill, Oxford; 2000.

12. Evans WC. Trease and Evan's Pharmacognosy. $5^{\text {th }}$ ed, Haarcourt Brace and Company; 2002. p. 336.

13. Singh RP, Magesh S and Rakkiyappan C. Ginger (Zingiberofficanale) Root extract: A source of silver nanoparticles and their applications. Int.Journal of Bio-Eng. Science and tech 2011; 2(3): 75-80.

14. Thirumurgan A, Tomy NA, Jai Ganesh R and Gobikrishnan S. De Phar Chem 2010; 279-284.

15. Shankar SS, Rai A, Ahmad A and SastryMJ. J Collid Interface Sci 2004; 496-502.

16. Avilajerley A and Anita marget A. Mycosynthesis of silver nanoparticles and antibacterial effects in wound dressing. International ,journal of Pharm. Sciences and researches 2012; 3(6): 1698-1704.

Cite this article as:

EnamalaNarmadha, Hemashenpagam N, SathiyaVimal. S, VasanthaRaj S. Characterization of papaya fruit mediated silver nanoparticles and evaluation of its antimicrobial and wound healing activity. Int. Res. J. Pharm. 2013; 4(7):166-169 http://dx.doi.org/10.7897/2230-8407.04737 